\title{
Article \\ Utilisation of Moon Regolith for Radiation Protection and Thermal Insulation in Permanent Lunar Habitats
}

\author{
Yulia Akisheva*(D) and Yves Gourinat \\ Department of Mechanics, Structures and Materials, ISAE-SUPAERO, l'Institut supérieur de l'aéronautique et de \\ l'espace, 10 Avenue Edouard Belin, 31055 Toulouse, France; yves.gourinat@isae-supaero.fr \\ * Correspondence: yulia.akisheva@gmail.com
}

check for updates

Citation: Akisheva, Y.; Gourinat, Y. Utilisation of Moon Regolith for Radiation Protection and Thermal Insulation in Permanent Lunar Habitats. Appl. Sci. 2021, 11, 3853. https://doi.org/10.3390/app11093853

Academic Editor: Marwan Al-Haik

Received: 30 March 2021

Accepted: 20 April 2021

Published: 24 April 2021

Publisher's Note: MDPI stays neutral with regard to jurisdictional claims in published maps and institutional affiliations.

Copyright: (c) 2021 by the authors. Licensee MDPI, Basel, Switzerland. This article is an open access article distributed under the terms and conditions of the Creative Commons Attribution (CC BY) license (https:/ / creativecommons.org/licenses/by/ $4.0 /)$.

\begin{abstract}
In the context of a sustainable long-term human presence on the Moon, solutions for habitat radiation and thermal protection with regolith are investigated. Regolith compression is studied to choose the optimal density-thickness combination in terms of radiation shielding and thermal insulation. The applied strategy is to protect the whole habitat from the hazards of galactic cosmic rays and design a dedicated shelter area for protection during solar particle events, which eventually may be a lava tube. Simulations using NASA's OLTARIS tool show that the effective dose equivalent decreases significantly when a multilayer structure mainly constituted of regolith and other available materials is used instead of pure regolith. The computerised anatomical female model is considered here because future missions will be mixed crews, and, generally, more sex-specific data are required in the field of radiation protection and human spaceflight. This study shows that if reasonably achievable radioprotection conditions are met, mixed crews can stay safely on the lunar surface. Compressed regolith demonstrates a significant efficiency in thermal insulation, requiring little energy management to keep a comfortable temperature inside the habitat. For a more complete picture of the outpost, the radiation protection of lunar rovers and extravehicular mobility units is considered.
\end{abstract}

Keywords: radiation protection; thermal insulation; habitat construction; Moon; human spaceflight; regolith

\section{Introduction}

The hostile space environment poses several technological problems for long-term human exploration. Thermal cycling and ionising radiation are two extreme challenges on the Moon, which, when considered together, make up one complex puzzle for engineers and architects of habitat construction to solve. Radiation exposure causes short- and long-term effects on the health of astronauts, e.g., cataract formation and carcinogenesis, respectively, and a prolonged exposure may pose serious threats to life [1-3]. Temperature extremes of $-170^{\circ} \mathrm{C}$ and $113^{\circ} \mathrm{C}$ [4] between the night and the day impose thermal stresses on materials and thermal cycling on the Moon can lead to thermal fatigue, potentially originating crack formation and propagation, thus presenting a threat to surface constructions. This study balances out the benefits of regolith utilisation as the main material for protection against galactic cosmic rays (GCR) and solar particle events (SPE) on the one hand, and for an adequate thermal environment inside the habitat on the other. Such an approach aims to outline the potential merit of regolith utilisation in habitats from a double point of view, ultimately allowing the definition of specifications for the architects designing the construction of future habitats on the Moon.

Studies continuously evaluate the use of loose regolith, either through piling it up on top of an inflatable habitat, 3D printing, sintering or melting [5-8]. The baseline of such designs relies on multilayer structures, using complimentary materials, such as polyethylene bags and aluminium foils, to contribute to the wall's stress resistance and thermal protection. Polyethylene and aluminium are used as standard materials in space 
exploration $[9,10]$. In this paper, properties to further enhance radiation protection such as regolith compaction and multilayer materials are evaluated. The work presented here outlines different options for regolith compaction and utilisation which scopes out the architectural liberty in habitat construction. The available compression techniques and the amount of compaction that will be possible to make in situ will largely define the shape of future lunar habitats. The added value of this paper is in the proposal of a reasonably achievable protective layer from radiation which also satisfies the thermal insulation of the habitat.

Regolith in a multilayer structure with aluminium and polyethylene, with regolith as the majority of the wall's thickness is evaluated for radiation protection of a lunar habitat; and thermal insulation properties are modelled during the 28 Earth days lunar cycles in order to anticipate what the temperature stability inside the habitat will be like. This study calculates the blood forming organs (BFO) dose and the effective dose equivalent in the computerised anatomical female (CAF) [11,12]. SPE-induced BFO doses are considered to investigate the doses for short-term non-cancer effects. SPEs are short-term events which may present considerable harm to astronaut health. The authors anticipated that the SPE-induced doses would impose a larger constraint on regolith thickness than the GCRinduced doses. The latter ones result from an omnipresent continuous source of radiation, and the effective dose equivalent is thus calculated. As NASA's Artemis program [13] and following international Moon exploration will have mixed crews, and it is recognised that more sex-disaggregated data are required to draws conclusions on gender-specific radiation sensitivity [14] it is appropriate to base radiation protection for exploration type missions on the female model.

The results are translated into quantitative recommendations on the minimum thicknesses and densities that the regolith layers should have in habitats for a generic long-term mission scenario on the Moon. The baseline taken here is that the level of protection in the Moon habitats should be comparable to that on the ISS in terms of equivalent doses for 6-month-long missions, because it shows that these conditions are safe for mixed crews. The recommendations lay out the basis for future architectural analyses of possible habitats. This paper takes an engineering approach to addressing the question of regolith utilisation for radiation protection and thermal insulation in habitat construction.

\section{Considerations to Set a Habitat Protection Strategy}

\subsection{Passive Shielding}

Radiation protection can take several forms, mainly divided into passive and active with electrostatic, magnetic and plasma shielding $[3,15]$. This work studies the passive shielding which is based on the ability of a chosen material to stop or decelerate charged particles and attenuate the dose accumulated in the target placed behind the shield. For human outposts on the Moon, passive shielding from radiation also plays the role of structural support and protection from micro meteoroid impacts which altogether may require a habitat to be covered with a dense or thick material. The in-situ resource utilisation (ISRU) is key in achieving this in order to reduce transportation of materials from the Earth and mission costs $[6,16]$. Regolith is abundant on the surface of the Moon and it may serve as the main material for protecting habitats from the space environment [16]. When processed, i.e., molten, sintered, mixed with binders, loose regolith can become a useful solid material $[7,17,18]$. This concept relies of the development of ISRU technologies.

Following the As Low As Reasonably Achievable (ALARA) principle of NASA, additional materials such as aluminium, polyethylene, Kevlar, etc., are repeatedly investigated in literature to determine how their utilisation may optimise the radiation protection of habitats and in deep space [10,19]. Hydrogen-rich materials, e.g., water and polyethylene, rank high among others $[9,10]$ because they have more nuclei in the path of the particles for the same shield thickness in mass per unit area. This helps to break up the heavy nuclei. These materials contain few neutrons which leads to fewer secondary neutrons and as neutrons are a big concern for the effective dose [1], it is an important factor in radiation 
protection. In this respect, hydrogen ${ }^{1} \mathrm{H}$ is the best option because it contains no neutrons (also called "protium"). Furthermore, nuclei with lower atomic mass have a smaller atomic charge, which makes them less effective in producing secondary emissions.

\subsection{Accepted Dose Limits}

Currently, national space agencies work internationally towards establishing norms and recommendations for dose limits on exploration type missions [20]. For lunar exploration, low-Earth orbit (LEO) limits are recommended to be used for doses to the skin, BFO, and ocular lenses [6]. NASA's 30-day exposure limit of $250 \mathrm{mSv}$ may not be exceeded on the envisioned missions. The dose limit for short term non-cancer effects on BFO is 250 mGy-Eq. NASA also applies the accepted risk of $3 \%$ increase of radiation exposure-induced death (REID) evaluated at 95\% confidence level. These limits as well as the annual and career exposure ones can be found in NASA's Standard 3001 Volume 1 on crew health [21]. Following these dose limits and the ALARA principle, this works sets out to compare the outposts on the Moon to that on the ISS. The overarching goal of not exceeding $150 \mathrm{mSv}$ per 6-month stay is set.

\subsection{SPES}

The SPEs are mainly particles accelerated through the interplanetary space from a coronal mass ejection (outbursts of gamma radiation, $\mathrm{X}$ rays and radio waves) or during a high solar activity. The SPEs contain mostly protons and include helium ions as well as highly charged and energetic (HZE) ions. The fluence of protons above $30 \mathrm{MeV}$ can exceed $10^{10} \mathrm{~cm}^{-2}$ in several hours or days and particles above $50 \mathrm{MeV}$ can penetrate spacesuits and spacecraft [22]. Protons above $10 \mathrm{MeV}$ can penetrate spacesuits and reach the lens of the eye [1].

A mission's SPE design basis represents the maximum number of different SPEs with their energy levels encountered during the entire mission. Measurements and estimations are used to predict the design basis for a given future mission, depending largely on the mission's launch year and duration with respect to the solar activity. Knowing the solar cycle and the relative occurrences of these SPEs can get the first approximation to represent the design basis. What is really meant by a design basis is that no particles with higher energies and fluences than described in the model should be encountered during the mission, with a certain level of confidence. Ref. [23] argues that, for a Moon mission, it would mean $1 \mathrm{~Sv}$ of exposure, which is the career limit for astronauts of most national space agencies [24].

Solar cycle 25 (2020-2031) is expected to be similar to cycle 24 when the Sun's activity was below average. The cycle began with a solar minimum and experts anticipate that the sunspot maximum will occur between 2023 and 2026 [25]. Based on the prediction that cycle 25 will have low activity and the fact that a large SPE is a random event of low probability for any given mission [26], the next solar cycle may be the perfect time for a long-term return of humans to the Moon, on the scale of the space age.

\subsection{GCR}

The GCR are baryons (mainly hydrogen protons and alpha particles, as well as heavy nuclei) and electrons accelerated from outside our solar system which are extremely energetic and penetrative. While a mission during a solar minimum (the lowest level of solar activity during a solar cycle of 11 years) seems reasonable from the encounter of the SPE point of view, it implies harsher conditions from the GCR point of view. In fact, the GCR cycle is inversely related to the solar cycle. As the cosmic particles enter the solar system, they interact with the solar magnetic field (which is coupled to the solar wind) which causes the GCR to lose energy. Particularly, it is the lower energy GCR particles that are affected the most. At $100 \mathrm{MeV} / \mathrm{u}$, the fluence drops by a factor of 10 during the solar maximum and at $4 \mathrm{GeV} / \mathrm{u}$, it drops by approximately $20 \%$ [1]. 
If cycle 25 will indeed be similar to cycle 24 , which is normal because the two in fact make up one complete cycle of the Sun's magnetic polarity (cycle of 22 years), then we can expect an increase of the GCR fluence. In 2009, the GCR intensities increased by 19\% [27].

A thin protective layer can help reduce the exposure to high-energy primary particles but as they decelerate, secondary particles are created from nuclear interactions between the GCR and the material. These secondary emissions, often neutrons, present a great danger to the health of astronauts because while they have lower energies, their quality factors are generally higher than those of the primary radiations. Ref. [2] states that the secondary neutron production increases with the mass number of the shielding material's atoms and it can be large for aluminium or regolith, which ultimately may increase the risk of radiation-induced carcinogenesis. Based on the BFO dose simulated for the SPE of February 1956, [28] concludes that when aluminium and regolith shielding thickness is elevated, neutrons contribute up to half the total dose. More recent studies [29] show that the portion of $<200 \mathrm{MeV}$ of the neutron energy spectrum accounts for half of the biological neutron exposure in deep space.

\subsection{Our Habitat Protection Strategy}

The baseline of our protection strategy is to provide astronauts with a shield to mitigate the effects of the ever-present hazards of galactic cosmic rays everywhere in the habitat. In the case of solar particles events, a dedicated shelter area for protection is envisioned to mitigate the short-term effects of the highly energetic SPEs. Several historical events are simulated against the design to ensure the examination of different types of SPEs, since they differ in proton energy, flux and duration. BFO doses are calculated for these scenarios to determine the wall thickness and regolith utilisation in the SPE shelter.

The SPE shelter will have to comfortably host astronauts from several hours up to a few days. It should be equipped with an airlock system through which the astronauts on extravehicular activities can quickly come back. Ideally, this system should have the capability to be docked with the surface transport vehicle that the crew will use. Since at the time of an SPE or high solar activity an astronaut can be far from the base, a solution is also proposed for surface transport vehicle radiation protection. This protection is only a short-term solution and the astronauts are required to return to the base and shelter immediately if an alert is received.

Lava tubes can also be considered for temporary shelters during periods of high solar activity and SPEs. Lunar lava tubes have been a study case for human habitats over many years $[30,31]$ and continuous research indicates how below a few metres underground the doses are reduced to comfortable background levels [32]. However, astronauts cannot spend all their time exploring and living in caves, and surface exploration is required.

\section{Regolith Model}

What is referred to as lunar regolith is the top layer of the lunar megaregolith. It is a mixture of shattered and fragmented lunar crust and impact material. Toward the end of the heavy bombardment era at $\sim 3.8-3.9 \mathrm{Ga}$, the impactors evolved into smaller projectiles [33]. The topmost layer of regolith consists of macroscopic, loose and finegrained particles whose fragmentation and evolution are due to projectiles typically of 0.1-10 $\mathrm{m}$ in diameter [33]. The composition of lunar regolith has been studied through Earth-bound observations, from satellite data and, most importantly, from sample return. This work uses the oxide distribution as specified in Table 1 . That is the highlands regolith composition as found and averaged from the Apollo missions [34]. The nominal volumetric density of highlands regolith is $1.6 \mathrm{~g} / \mathrm{cm}^{3}$ here. 
Table 1. Highlands regolith composition averaged from the Apollo missions' sample return [34].

\begin{tabular}{ccccccc}
\hline \multicolumn{7}{c}{ Oxide Quantity (\%) } \\
\hline $\mathrm{SiO}_{2}$ & $\mathrm{Al}_{2} \mathrm{O}_{3}$ & $\mathrm{TiO}_{2}$ & $\mathrm{FeO}$ & $\mathrm{MnO}$ & $\mathrm{MgO}$ & $\mathrm{CaO}$ \\
45 & 27 & 0.7 & 5 & 0.3 & 6 & 16 \\
\hline
\end{tabular}

\section{Radiation Analysis}

\subsection{Radiation Models}

The shielding and radiation environments are simulated with the On-Line Tool for the Assessment of Radiation In Space (OLTARIS, TARIS 4.01) developed by NASA [35], TARIS version 4.01. The tool runs a deterministic High Z and Energy TRanNsport (HZETRN) $3 \mathrm{D}$ code $[36,37]$ which solves the Boltzmann equation using continuous slowing down approximation. The BFO dose in grey-equivalent and effective dose equivalent in $\mathrm{mSv}$ are calculated for the CAF model [11,12], the latter one using the ICRP 60 quality factors. The doses are calculated as a function of shielding measured in $\mathrm{g} / \mathrm{cm}^{2}$. To convert from aerial densities presented in graphs to walls or regolith thicknesses in $\mathrm{cm}$, it is required to divide the aerial density by the nominal volumetric density of regolith.

Symmetrical spherical geometries of the shielding are used to approximate all habitats in the middle of which the CAF phantom is found vertically oriented, head upwards. Concentric spheres of appropriate thicknesses are used to define the different layers of the habitat wall, such as the outer regolith shell and the aluminium and polyethylene shells. Thickness distribution files were produced for the spheres, and the reader is encouraged to use the OLTARIS user guide for their utilisation details.

Unless stated otherwise, the GCR conditions are simulated for 180 days at the solar minimum parametrised with the solar modulation parameter of $475 \mathrm{MV}$ and using the Badhwar-O'Neill (BON) 2014 GCR model [38]. The solar modulation is a temporal parameter related to the solar activity through its cycle, which modulates the total flux and differential energy spectrum of GCR in the heliosphere. Here, $475 \mathrm{MV}$ were chosen to roughly represent a period of solar minimum based on observations in [39]. The model is implemented in OLTARIS, which reports accuracy of the GCR environment at 1 astronomical unit (AU) within $10 \%$ or less. Free space galactic rays and solar particles at $1 \mathrm{AU}$ follow the specified ray distributions from free space to the target point on the habitat. Ray distribution files can be downloaded and modified from OLTARIS database; they are necessary for ray-by-ray calculations which are used for effective dose equivalent and can also be used for BFO doses. This work uses the ray-by-ray option throughout.

OLTARIS' GCR models for the lunar surface consider the albedo. The program uses thickness distributions files written to represent a habitat to apply either the free space environment at $1 \mathrm{AU}$ for rays emanating from space to a point on the habitat or neutron albedo for surface-pointing rays. Lunar albedo is calculated for GCR models by applying the free-space GCR to the lunar regolith [35,40].

Simplistic spherical habitats on the surface of the Moon were simulated for the following SPEs:

- August 1972 King [41], which is widely regarded as the largest of the space age;

- February 1956 LaRC [42], which is marked particularly for the elevated flux of protons of energies above $500 \mathrm{MeV}$;

- October 1989 [43], which is categorised in the energy band of 5-100 MeV.

Ref. [44] explains that the SPE of August 1972 dominated the cumulative solar energetic particle contribution of solar cycle 20 and that this was the largest event in space exploration times in its energy range and for energies relevant to spacecraft components. The October 1989 event is the largest of the past 40 years in its energy range [44]. The largest uncertainties in SPE models are in the high energy tails as exponential models are used to curve fit data. 
Lava tubes are simulated in a simplistic way as spheres. The difference to the GCR and SPE cases is that for lava tubes only regolith is used and its thickness is adjusted to represent underground tunnels.

The lunar rover and the extravehicular mobility units (EMUs) also use spherical geometries for dose calculations. Different materials are simulated as consecutive concentric spheres of appropriate thicknesses, for example an EMU has relatively thin ones representing the protective suit layers. In all simulations of this paper, the phantom is placed in the same manner inside the spheres, as described above.

\subsection{Radiation Simulations Results}

\subsubsection{GCR Effective Dose Equivalent on the Moon}

Figure 1 illustrates the results of GCR simulations for a lunar habitat made of highlands regolith. Figure 1a shows results against the areal thickness in $\mathrm{g} / \mathrm{cm}^{2}$ to demonstrate the local maximum. Figure $1 \mathrm{~b}$ presents the same results against the thickness of the regolith sphere in $\mathrm{cm}$. It illustrates vividly how compacting regolith is an effective technique for dose reductions if the same wall thickness is kept, which may have important implications for the architectural freedom and choices for the habitat. Beyond the point of the local dose maximum, the dose has a general trend to attenuate. It can be argued that the dose build-up at around $100 \mathrm{~g} / \mathrm{cm}^{2}$ in Figure $1 \mathrm{a}$ of regolith shielding is linked to the production of slow and fast secondary neutrons which are most dangerous to the human body, as reflected in the radiation weighting factors presented in Figure 2. The authors of [6] argue that beyond $100 \mathrm{~g} / \mathrm{cm}^{2}$ of aluminium or lunar regolith shielding, the dose is mainly due to secondary neutrons and secondary radiation from their reactions in the body. Protons of energies up to several hundred $\mathrm{MeV}$ produce secondary protons, neutrons, alpha particles, etc. [6]. Protons of higher energies are stopped further into the material, beyond the local maximum. However, this phenomenon is not only dependent on the incoming radiation energy and the thickness of shielding but also on the nature of the shielding, as polyethylene does not appear to have any local maximum, as demonstrated in Figure 3.

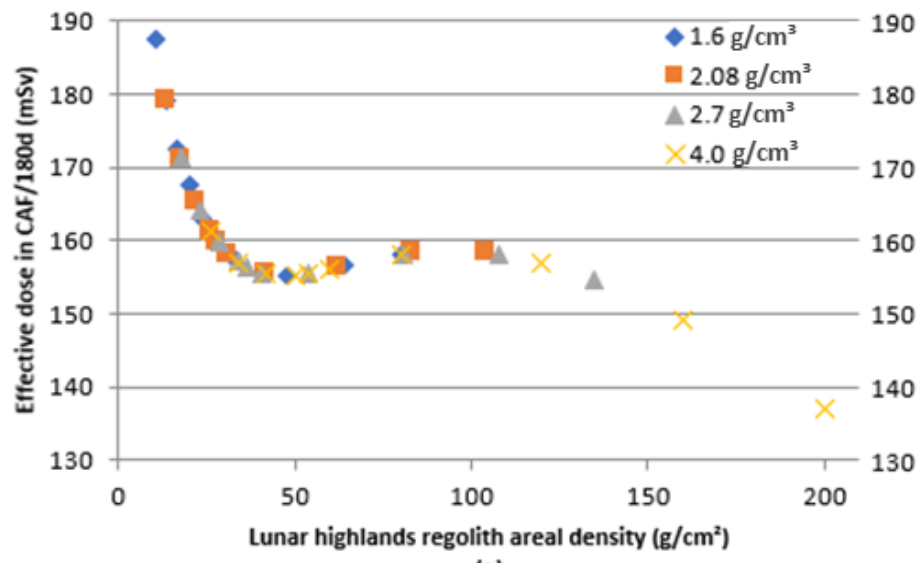

(a)

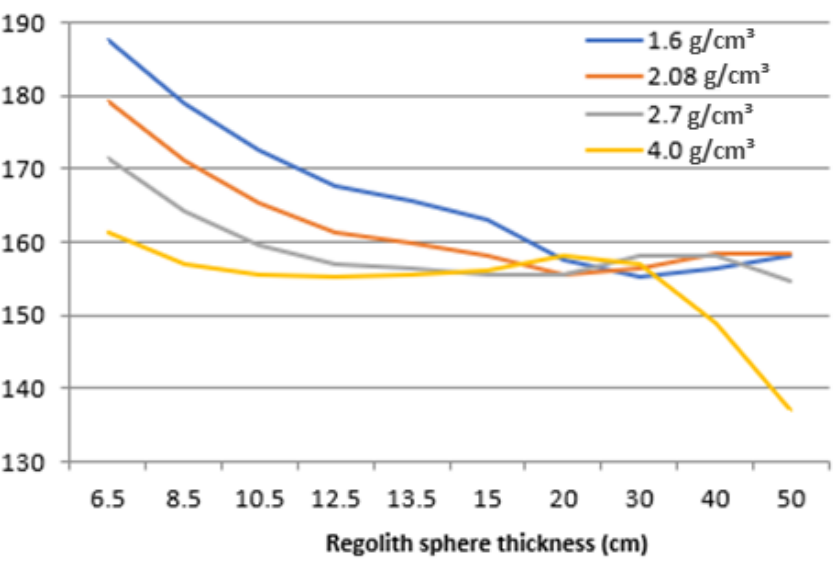

(b)

Figure 1. Effective dose equivalent in CAF as a function of highlands regolith areal density (a) and regolith sphere thickness (b) for different volumetric densities for the solar minimum GCR BON 2014 spectrum for 180 days on the Moon.

Polyethylene $\mathrm{CH} 2$ is hydrogen-rich which leads to lower production of secondary neutrons [9]. Furthermore, carbon and hydrogen do not have significant resonances in their nuclear structure to interact with secondary neutrons in the structure as the heavier atoms do [29], and carbon tends to disintegrate into helium nuclei and produce no neutrons [9]. These beneficial properties of polyethylene make it a favourable radiation protection material. However, scattering can occur, and a highly energetic neutron can produce a proton of the same energy which will lead to a dose build up. Furthermore, some particles will have high enough energies that they will create ballistic collisions and create 
secondary neutrons. Nevertheless, polyethylene will generate fewer secondary neutrons than aluminium.

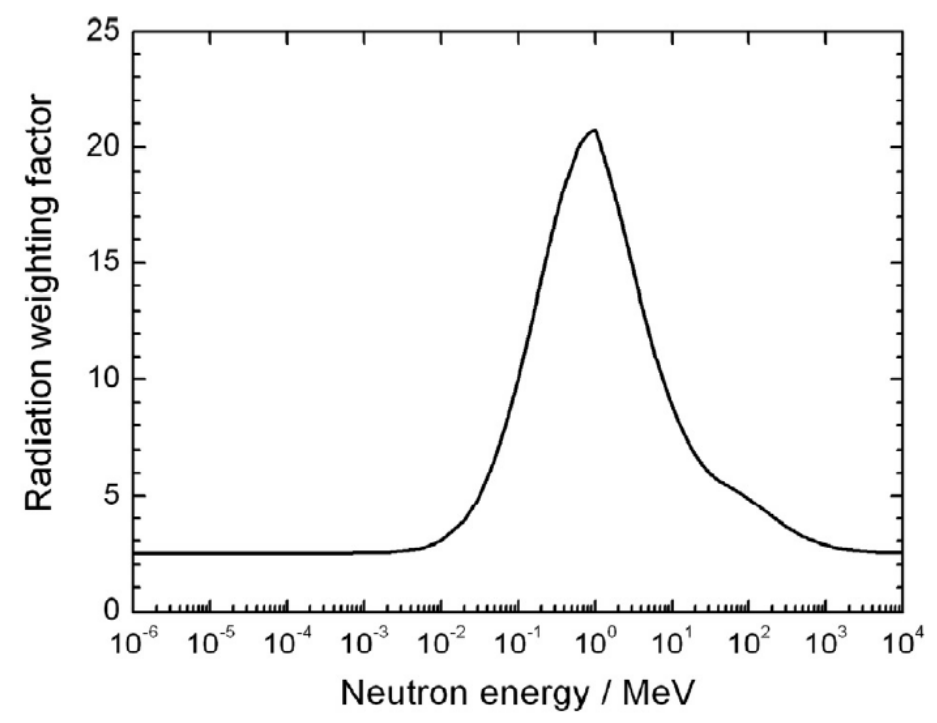

Figure 2. Radiation weighting factor for neutrons vs. neutron energy, figure taken from [1].

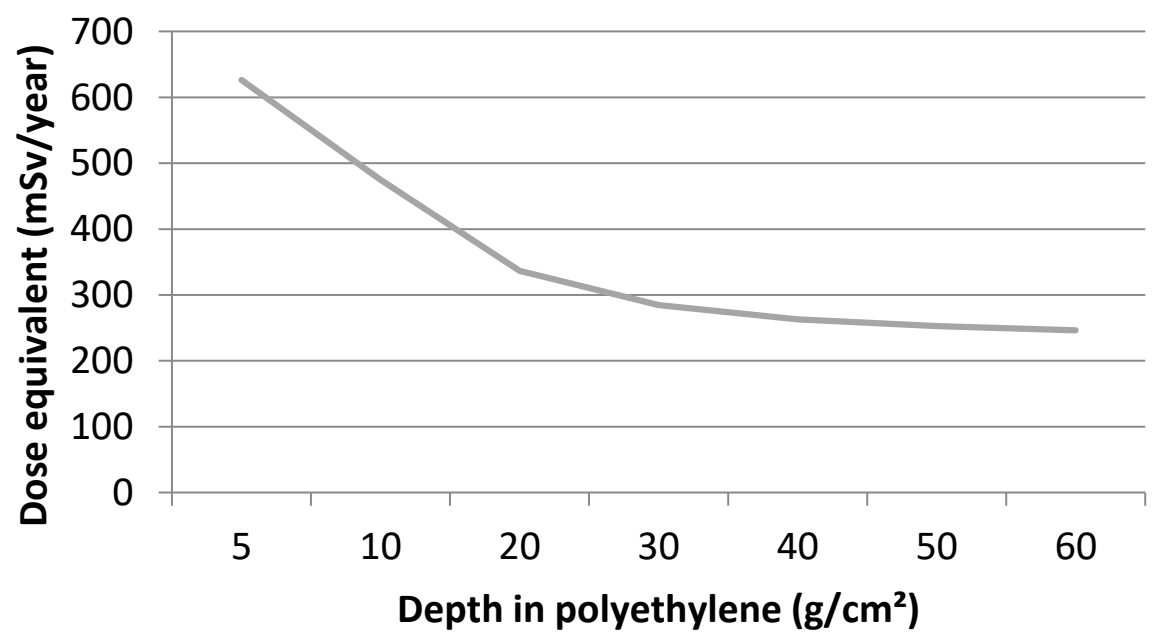

Figure 3. Dose equivalent in polyethylene for the GCR BON 2010 spectrum in free space at 1 AU.

Based on these considerations, a multilayer structure with regolith as the main thick layer, followed by $3 \mathrm{~mm}$ of aluminium for further structural rigidity and finally, $5 \mathrm{~cm}$ of polyethylene has been modelled. Multilayer simulations' results for regolith/aluminium/ polyethylene shields are shown in Figure 4. In contrast to pure regolith, there is no more local maximum in the effective dose equivalent curve, which suggests that the polyethylene layer helps attenuate the dose build-up. Instead, the region of the build-up is marked with a slow dose decline when compared to low areal densities. The overall trend up to high regolith densities is declining. The dose attenuation at thick areal densities follows the trend dominated by the thick regolith layer and the general decline suggests that the dose may be even lower in deep lava tubes. 


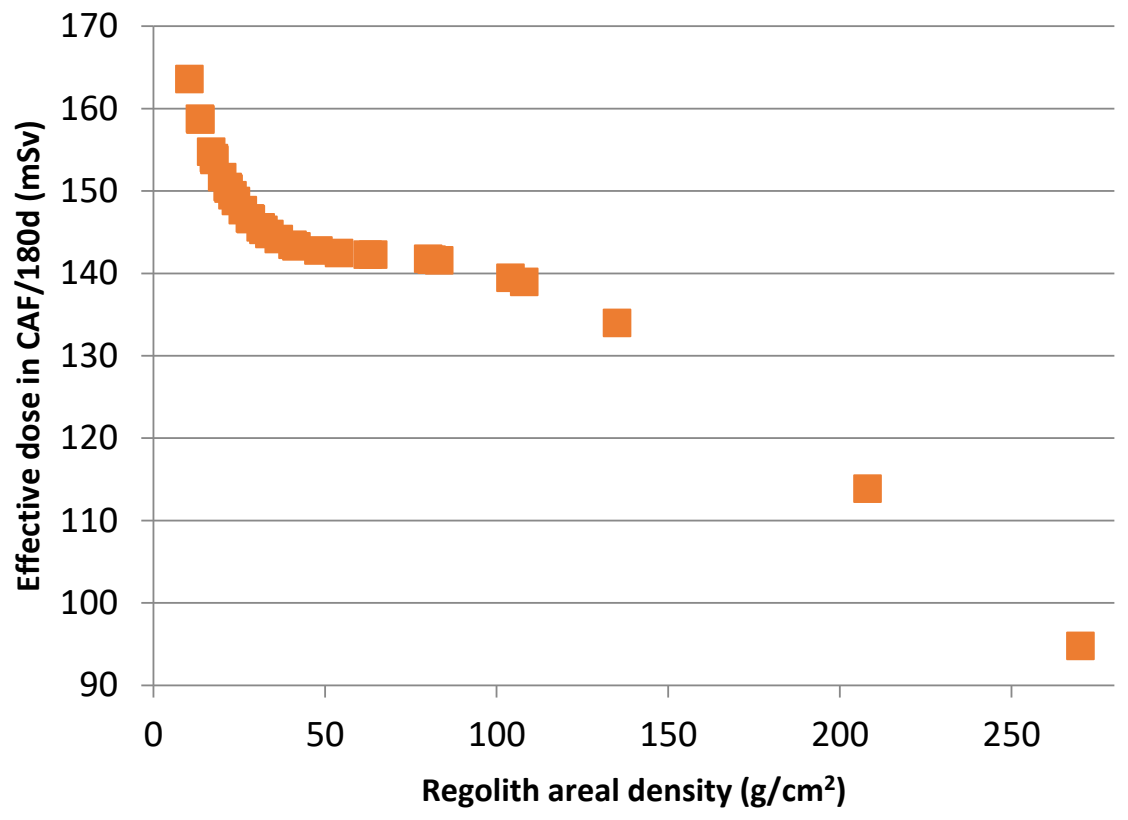

Figure 4. Effective dose equivalent in CAF behind multilayer shielding (regolith followed by $3 \mathrm{~mm}$ of aluminium and $5 \mathrm{~cm}$ of polyethylene) as a function of highlands regolith areal density for the solar minimum GCR BON 2014 spectrum after 180 days.

To simulate the radiation shielding of a lava tube, $1.6 \mathrm{~g} / \mathrm{cm}^{3}$ highlands regolith was tested at 300 and $1000 \mathrm{~g} / \mathrm{cm}^{2}$ corresponding to $1.88 \mathrm{~m}$ and $6.25 \mathrm{~m}$ respectively, where the effective dose equivalent drops significantly with depth, as shown in Table 2. Real lava tubes may extend far further and it is safe to assume that the deep basalt regolith is denser, which increases the areal density for a given thickness in metres. Therefore, the dose is a safe overestimation of the experienced dose.

Table 2. Effective dose equivalent in CAF in simulated lava tubes of highlands regolith for the solar minimum GCR BON 2014 spectrum after 180 days.

\begin{tabular}{cc}
\hline \multicolumn{2}{c}{ Effective Dose Equivalent in CAF/180d (mSv) } \\
\hline 1.88 m deep & 6.25 m deep \\
102.8 & 4.76 \\
\hline
\end{tabular}

It is evident that lava tubes provide strong competition for artificial passive shields, and just a few metres of soil reduce the effective dose equivalent more than 20 times. The $6.25 \mathrm{~m}$ tube can be a habitat with a comfortably low GCR-induced effective dose equivalent. Furthermore, the capacity of lava tubes to withstand meteoroid impacts increases significantly with their depths. However, with depth come new challenges in terms of providing all elements of life support under the surface and one cannot imagine that the explorer astronauts will either spend all their time or perform all scientific research underground.

\subsubsection{SPE Gy-equivalent Doses to BFO on the Moon}

Only multilayer structures were tested for habitat protection against SPEs. Figure 5 gives the calculated BFO dose as a function of regolith areal density, showing that low areal densities of regolith lead to high doses in BFO per event, particularly for the February 1956 SPE. 


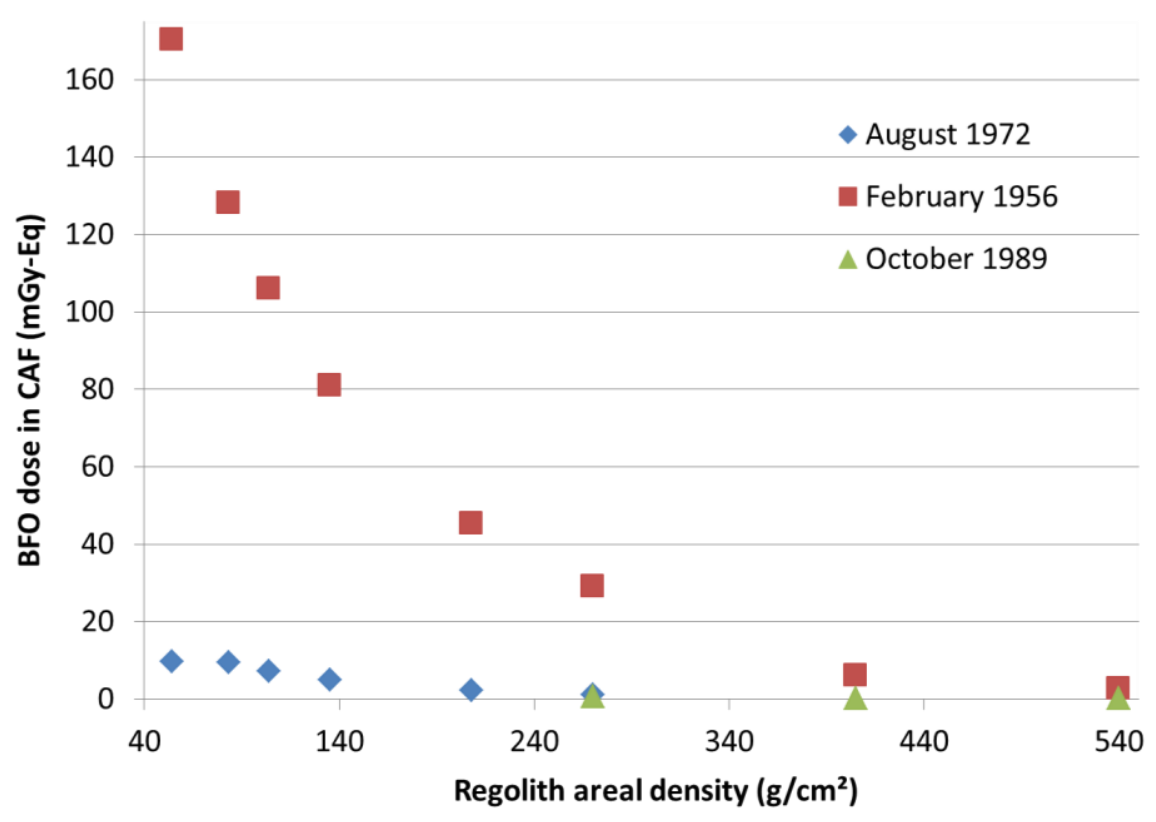

Figure 5. BFO dose in CAF behind multilayer shielding (regolith followed by $3 \mathrm{~mm}$ of aluminium and $5 \mathrm{~cm}$ of polyethylene) as a function of highlands regolith areal density for different historical SPE spectra.

The largest areal densities in Figure 5 correspond to two metres of $2.7 \mathrm{~g} / \mathrm{cm}^{3}$ compressed regolith. Then the doses are attenuated down to a few mGy-Eq on average. Thickening of the polyethylene layer up to $10 \mathrm{~cm}$ from the original $5 \mathrm{~cm}$ allows the dose to be further attenuated, as Table 3 indicates. The shelter's walls can be thickened with polyethylene as the mission progresses, where plastic waste can become the source of polyethylene. Refs. [45-47] studied the utilisation of trash for radiation protection and [45] suggested that condensed plastic waste be used for the SPE protection in deep space to the extent that it could even replace an initial water-based protection.

Table 3. BFO dose reduction due to polyethylene layer thickening in a multilayer material for SPE protection.

\begin{tabular}{|c|c|c|c|}
\hline \multirow{2}{*}{$\begin{array}{l}\text { BFO Dose in CAF } \\
(\mathrm{mGy}-\mathrm{Eq})\end{array}$} & \multicolumn{2}{|c|}{ Polyethylene Shielding Thickness (cm) } & \multirow{2}{*}{$\begin{array}{c}\text { Relative Change } \\
(\%)\end{array}$} \\
\hline & 5 & 10 & \\
\hline $\begin{array}{c}\text { August } 1972 \\
135 \mathrm{~g} / \mathrm{cm}^{2} \text { of regolith }\end{array}$ & 5.01 & 3.98 & 20.6 \\
\hline $\begin{array}{c}\text { February } 1956 \\
270 \mathrm{~g} / \mathrm{cm}^{2} \text { of regolith }\end{array}$ & 29.11 & 13.19 & 54.7 \\
\hline
\end{tabular}

As for the GCR, lava tubes are safer against the SPE. Table 4 summarises the doses in BFO and demonstrates how the dose reduces by three orders of magnitude in a $6.25 \mathrm{~m}$ deep tube. Therefore, if any lava tubes are present in the habitation zone, they may be considered as potential candidates for temporary radiation shelters.

Table 4. BFO dose in CAF in simulated lava tubes for different historical SPE spectra.

\begin{tabular}{|c|c|c|}
\hline \multirow{2}{*}{ SPE Spectrum } & \multicolumn{2}{|c|}{ BFO Dose in CAF (mGy-Eq) } \\
\hline & $300 \mathrm{~g} / \mathrm{cm}^{2}$ of Regolith & $1000 \mathrm{~g} / \mathrm{cm}^{2}$ of Regolith \\
\hline August 1972 & 1.22 & $2.44 \times 10^{-3}$ \\
\hline February 1956 & 29.3 & 0.374 \\
\hline October 1989 & 1.47 & $6.46 \times 10^{-3}$ \\
\hline
\end{tabular}




\subsubsection{Rover on the Lunar Surface}

Two shields were simulated for a representative rover for astronaut transportation on the Moon surface. Initially it was supposed that three-cm-thick rover shielding would suffice for temporary protection, but a one-day GCR simulation together with elevated doses from the SPE of August 1972 pointed towards the need for a supplementary polyethylene layer. The addition of a reasonable layer of polyethylene allows the SPE-induced dose to be brought down by $63 \%$ (see Table 5), given the fact that astronauts are only meant to use the rover for immediate transfer back to shelter once a high solar activity alert is received. The literature indicates that constant Sun surveillance allows the prediction of SPEs hours or days in advance due to the difference in the speed at which the electromagnetic information and solar protons propagate [48]. However, some outpost plans are likely to include large field exercises and far sample collection and, with the relatively low speed of rovers on extra-terrestrial terrains, it is advisable to take precautions for radiation protection of the surface transport vehicles and therefore the use of polyethylene is advised. three $\mathrm{cm}$ of aluminium shielding will contribute to a large mass of the machine thus limiting further its mobility, on top of low speeds generally available to rovers. Due to reduced mobility and potential SPE alerts, it is strongly advised to enhance the protection with a polyethylene layer, and future work will look into alternative materials to help reduce the rover mass.

Table 5. Effective and BFO doses in CAF for the lunar rover.

\begin{tabular}{|c|c|c|c|}
\hline \multirow{2}{*}{ Dose in CAF } & \multicolumn{2}{|r|}{ Shielding } & \multirow{2}{*}{$\begin{array}{c}\text { Relative Change } \\
(\%)\end{array}$} \\
\hline & Aluminium $(3 \mathrm{~cm})$ & Aluminium $(3 \mathrm{~cm})$-Polyethylene $(5 \mathrm{~cm})$ & \\
\hline Effective, GCR BON 20141 day (mSv) & 1.1 & 0.95 & 13.6 \\
\hline BFO, August 1972 SPE (mGy-Eq.) & 225.6 & 85.8 & 62 \\
\hline
\end{tabular}

\subsubsection{Extravehicular Mobility Units on the Moon}

On the Moon, astronauts are likely to be involved in extensive surface expeditions on a daily basis. Thus, contrary to extravehicular activities (EVA) at the ISS, a considerable amount of mission time will be spent under low radiation protection conditions of the suit. The use of Kevlar is not new in space, as it is one of the protective layers of the extravehicular mobility units. However, the utilisation of Kevlar can be enhanced and it can serve as radiation protection as well. Kevlar has radiation effectiveness comparable to that of polyethylene [19]. The layer of Kevlar can be thickened in EMUs for surface exploration on the Moon. For a simulation of the GCR conditions for six h on the Moon to represent an average EVA time, three layers of different kinds were considered as EMU materials, the in-most neoprene layer of $3 \mathrm{~mm}$ followed by silica aerogel and Kevlar $1 \mathrm{~mm}$ each. This gave $0.32 \mathrm{mSv}$ of the total effective dose equivalent, which when compared to $0.19 \mathrm{mSv}$ received by a fellow astronaut staying in the habitat behind a multilayer structure with $104 \mathrm{~g} / \mathrm{cm}^{2}$ of regolith suggests that the spacesuit protects one relatively well. The scenario is illustrated in Figure 6.

The calculated daily dose rate of $1.3 \mathrm{mSv} / \mathrm{d}$ falls within the reported Apollo range of $0.7-3 \mathrm{mSv} / \mathrm{d}$ [23], and as it converts to $0.38 \mathrm{mGy} / \mathrm{d}$, it is also in good agreement with the measurements of the Cosmic Ray Telescope for the Effects of Radiation (CRaTER) aboard the LRO with a very low altitude of $50 \mathrm{~km}$. The CRaTER measured $0.22-0.27 \mathrm{mGy} / \mathrm{d}$ [23] between 2009 and 2010, which is the solar minimum at the beginning of cycle 24. Therefore, the simulated surface exploration scenario can provide a robust estimation of the daily EVA contribution to the total effective dose equivalent, which is on the order of magnitude of $1-2 \mathrm{mSv} / \mathrm{d}$. 


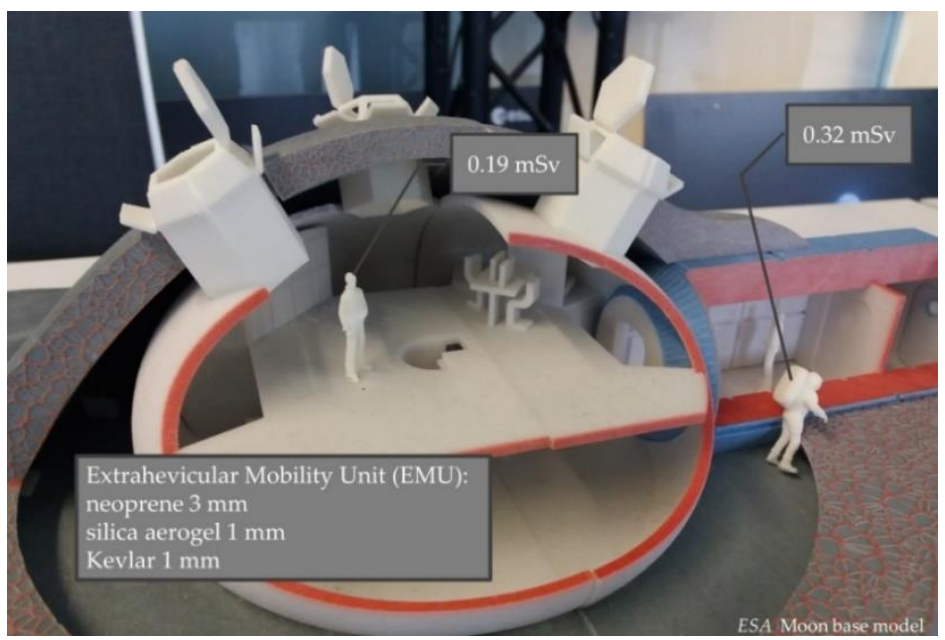

Figure 6. Illustration of EMU's effectiveness against radiation; the doses exhibited correspond to a 6-h period, which is the typical duration of an EVA; the image includes European Space Agency's (ESA) Moon base model.

\section{Thermal Analysis}

\subsection{Thermal Model-Lunar Environment}

Since the utilisation of regolith extends beyond radiation protection to structural support of the habitat and regolith makes up the majority of the building material in this study, its thermal insulation property is important to be assessed as the optimal thickness for radiation protection is sought. The 14-day night can be below $-180{ }^{\circ} \mathrm{C}$ and the 14 -day day can be over $100{ }^{\circ} \mathrm{C}$ at the lunar surface, whereas the inside temperature of the habitat should be maintained around $20^{\circ} \mathrm{C}$. The thermal model is attempting to calculate the thermal profile in a regolith wall covering the habitat, during several shifts between the lunar nights and days.

The one-dimensional time-dependent temperature profile is given by the Fourier equation:

$$
\frac{\partial T}{\partial t}=\frac{\lambda(T)}{\rho c_{p}} \frac{\partial^{2} T}{\partial x^{2}}
$$

where $T$ is the temperature of the wall as a function of time $t$ and the position $x$ in the wall, along the normal direction, $\lambda$ is the thermal conductivity which is temperature dependent, $\rho$ is the volumetric mass density and $c_{p}$ is the specific heat capacity.

The thermal conductivity $\lambda$ of the regolith is estimated from different sources. The Lunar Reconnaissance Orbiter (LRO) observations give values between 0.0001 and $0.03 \mathrm{~W} / \mathrm{mK}$ [49], and the measurements for the JSC-1A simulant exhibit values between 0.0019 and 0.0026 $\mathrm{W} / \mathrm{mK}$ [50]. In [51], the thermal conductivity of native highlands regolith is $0.01 \mathrm{~W} / \mathrm{mK}$. Here, it is considered as dependant on density and temperature as in [52] using [53] model:

$$
\lambda=K+B T^{3}
$$

where $K$ is the solid phonon conductivity and fixed at $0.015 \mathrm{~W} / \mathrm{mK}, B$ is the radiative conductivity factor and $\sim 10^{-11} \mathrm{~W} / \mathrm{mK}^{4}$ [52] and $T$ is the temperature.

Even in compressed regolith the morphology of the grains will remain close to that of native highlands regolith with the same shape and size of the grains embedded in a vacuum environment. In comparison, sintered or melted regolith building blocks will have massive and continuous morphologies with no vacuum inside which will lead to much higher thermal conductivity with an increase by one or two orders of magnitude as measured for processed simulants in [54]. 
The specific heat capacity of regolith depends on temperature, and some attempts have been made to define an empirical relationship, see expression in [49]. From the Apollo missions, temperature-dependent tables are available for the specific heat capacity. In the present calculations, the heat capacity was kept at a constant $840 \mathrm{~J} / \mathrm{kgK}$ [51]. These coefficients, along with the density, affect largely the solution to the transient state of the conductive heat transfer equation. Finally, the regolith diffusivity is taken as $\lambda(T) / \rho c_{p}$, which for $T=0$ gives $1.12 \times 10^{-8}$ and $4.5 \times 10^{-9} \mathrm{~m}^{2} / \mathrm{s}$ for non-compressed $\left(1.6 \mathrm{~g} / \mathrm{cm}^{3}\right)$ and compressed $\left(4.0 \mathrm{~g} / \mathrm{cm}^{3}\right)$ regolith respectively.

The initial conditions also affect the evolution of the temperature profile, however their effects fade out after few full cycles, i.e., lunar day and lunar night several times over, as will be shown in Section 5.2.

Five complete continuous thermal cycles are simulated with the following conditions:

- Initial Condition, $t=0:-70^{\circ} \mathrm{C}$ for all $x$. To start the calculation, it is assumed that the wall has homogeneous temperature, which is the approximate medium temperature between the outside extremes of the night and the day.

- Boundary Conditions:

- $x=0$ : Convection in the habitat is taken into consideration in this model as $d T / d x=-h(T(x=0)-20)$. Ref. [55] suggests taking a convective heat transfer coefficient, $h$, between 5 and $25 \mathrm{~W} / \mathrm{m}^{2} \mathrm{~K}$ for free convection in air. Since the convection will be low due to the reduced gravity on the Moon, the coefficient of $5 \mathrm{~W} / \mathrm{m}^{2} \mathrm{~K}$ is considered here.

○ $\quad x=L$ (where $L=0.4 \mathrm{~m}$ ): Radiant heat emitted from the outer surface as by the Stefan-Boltzmann law, $d T / d x=-\varepsilon \sigma T^{4}(x=0.4)$, where $\sigma$ is the Stefan-Boltzmann constant of $5.670374419 \times 10^{-8} \mathrm{Wm}^{-2} \mathrm{~K}^{-4}, \varepsilon$ and is the material's emissivity which is assumed to be 0.9 for highlands regolith here.

- $\quad x=L$ : During the day, two cases are considered here with a maximum solar heat flux of 600 and $1300 \mathrm{~W} / \mathrm{m}^{2}$ respectively.

The value of $1300 \mathrm{~W} / \mathrm{m}^{2}$ represents the approximated maximum flux, and $600 \mathrm{~W} / \mathrm{m}^{2}$ accounts for regions with increased lunar albedo and lower Sun elevation with respect to the surface. Depending on the Moon base position, the true solar flux will be a periodic function with maximum amplitude of approximately $1300 \mathrm{~W} / \mathrm{m}^{2}$ during the lunar day period followed by a null solar flux during the lunar night. The cycle has a period of 28 Earth days.

\subsection{Temperature Profile Results}

Figures 7 and 8 show the temperature profiles in a $0.4 \mathrm{~m}$ regolith wall after several lunar day-night cycles for two different solar heat flux corresponding to two different locations on the surface of the Moon, close to the equator $\left(1300 \mathrm{~W} / \mathrm{m}^{2}\right)$ and closer to the poles $\left(600 \mathrm{~W} / \mathrm{m}^{2}\right)$. The temperature inside the habitat $(x=0)$ is maintained constant at $20^{\circ} \mathrm{C}$. The profiles show clearly that the maximum external temperature depends on the solar flux $\left(120^{\circ} \mathrm{C}\right.$ for a $1300 \mathrm{~W} / \mathrm{m}^{2}$ flux against $50{ }^{\circ} \mathrm{C}$ for a $600 \mathrm{~W} / \mathrm{m}^{2}$ flux $)$. More interestingly, there is a significant difference in the constant temperature thickness close to the habitat between the non-compressed regolith wall with nominal density of $1.6 \mathrm{~g} / \mathrm{cm}^{3}$ and the compressed regolith wall with a density of $4.0 \mathrm{~g} / \mathrm{cm}^{3}$. In the latter case, more than half of the wall does not undergo the large external temperature shifts between the lunar days and nights. Similar insulating property is observed for non-compressed regolith, however, there is a beneficial gain of about $10 \mathrm{~cm}$ of isothermal behaviour in the compressed case. It provides another reason to compress regolith for Moon base construction on top of the conclusions from radioprotection studies. 


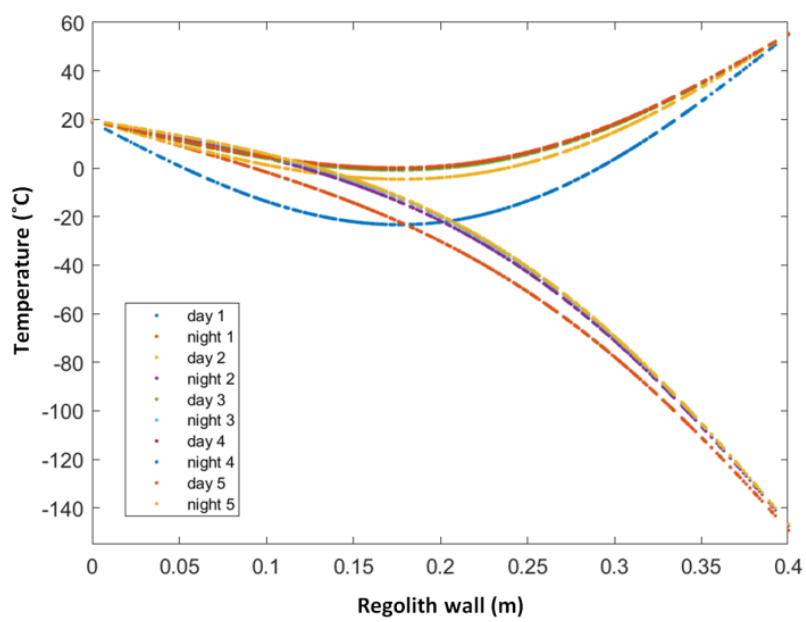

(a)

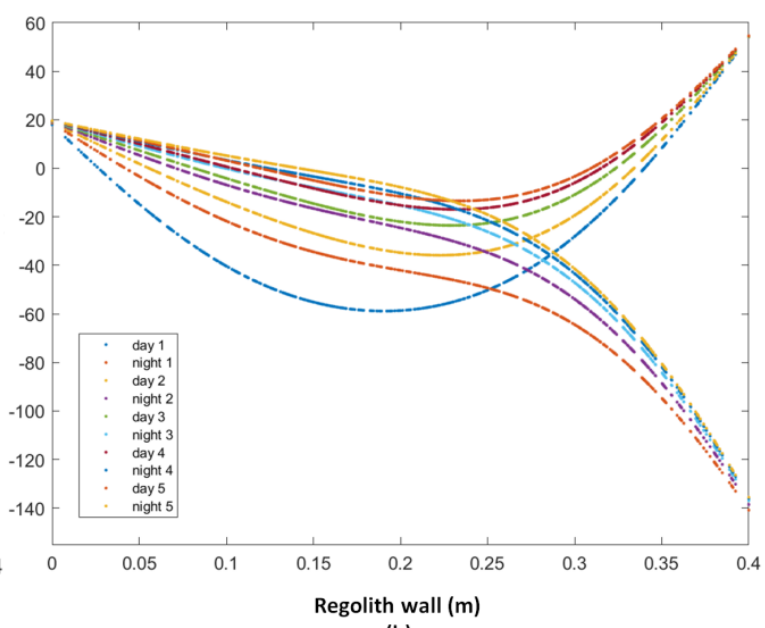

(b)

Figure 7. Temperature profiles through non-compressed $\left(1.6 \mathrm{~g} / \mathrm{cm}^{3}\right.$, image a) and compressed $\left(4.0 \mathrm{~g} / \mathrm{cm}^{3}, \mathrm{image} \mathbf{b}\right)$ highlands regolith walls with the solar heat flux of $600 \mathrm{~W} / \mathrm{m}^{2}$.

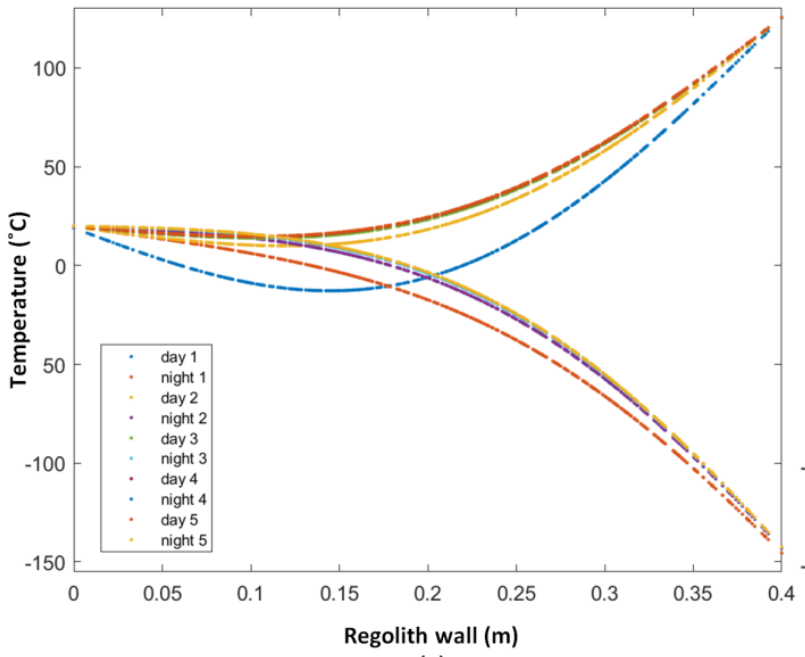

(a)

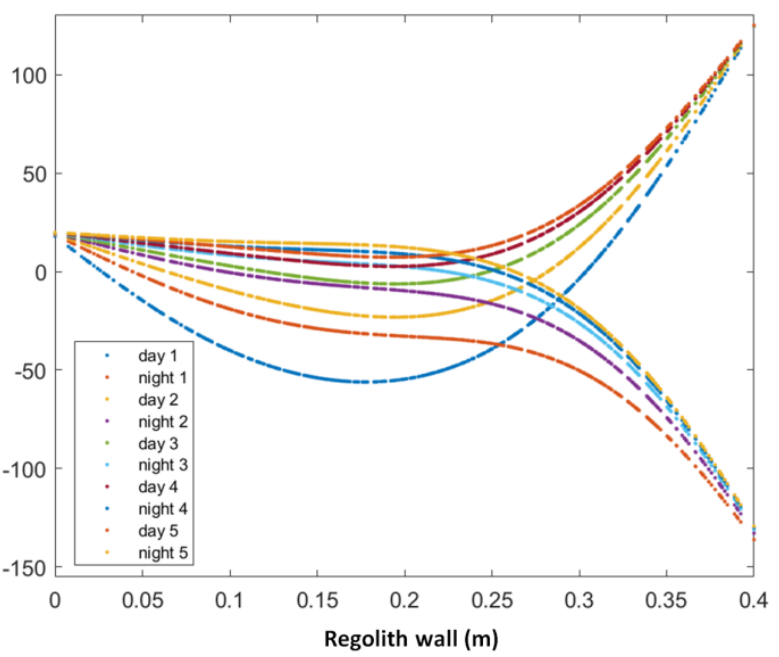

(b)

Figure 8. Temperature profiles through non-compressed $\left(1.6 \mathrm{~g} / \mathrm{cm}^{3}\right.$, image a) and compressed $\left(4.0 \mathrm{~g} / \mathrm{cm}^{3}\right.$, image b) highlands regolith walls with the solar heat flux of $1300 \mathrm{~W} / \mathrm{m}^{2}$.

To keep $20^{\circ} \mathrm{C}$ inside, a source would be required to compensate for the heat escaping through the wall. The tangents to the night 5 profiles at $x=0 \mathrm{~m}$ give temperature gradients which are used in the Fourier's law to calculate the escape fluxes in the cases of 600 and $1300 \mathrm{~W} / \mathrm{m}^{2}$ of solar heating. To estimate the required heating, a cylinder with a 5-m diameter and 5-m height is taken for reference. The results are summarised in Table 6, which indicates how little heating will be required thanks to the insulating properties of highlands regolith.

This study points to the remarkable insulation property of highlands regolith (specifically when it is compressed) and to the fact that only the outmost part of compressed regolith needs to be upsized against harsh thermal cycling. After the effect of the initial conditions wears off (here, $-70^{\circ} \mathrm{C}$ after two cycles), approximately half the wall keeps its temperatures with small fluctuations between the night and the day. 
Table 6. Heating required to keep $20^{\circ} \mathrm{C}$ inside a lunar habitat with a highlands regolith wall.

\begin{tabular}{|c|c|c|c|c|}
\hline & \multicolumn{2}{|c|}{ Non-Compressed Regolith $\left(1.6 \mathrm{~g} / \mathrm{cm}^{3}\right)$} & \multicolumn{2}{|c|}{ Compressed Regolith $\left(4.0 \mathrm{~g} / \mathrm{cm}^{3}\right)$} \\
\hline Solar flux $\left(\mathrm{W} / \mathrm{m}^{2}\right)$ & 600 & 1300 & 600 & 1300 \\
\hline Temp gradient $\left({ }^{\circ} \mathrm{C} / \mathrm{m}\right)$ & -143 & -45 & -136.6 & -35 \\
\hline Escape flux $\left(\mathrm{W} / \mathrm{m}^{2}\right)$ & 2.145 & 0.675 & 2.05 & 0.525 \\
\hline Heating req. (W) & 252.7 & 79.5 & 241.4 & 61.9 \\
\hline
\end{tabular}

\section{Discussion}

The results of this work are continuously translated into quantitative recommendations on regolith compression and optimal wall thickness for effective radiation protection and thermal insulation of a habitat on the Moon. Such engineering approach lays the foundation for architectural specifications to habitat construction. Future work will focus on diminishing secondary emissions and a more comprehensive thermal analysis. Different candidate locations will be analysed with respect to solar heat flux variations during the lunar day and with respect to local lunar albedo for highlands and mare terrains. However, it appears clearly that compressed highlands regolith will act as a good thermal insulator, leading to very limited heat losses out of the habitat during lunar day and night cycles.

Looking at two radiation scenarios, namely GCR and SPE, generates an understanding of the different regolith utilisations required for a holistic radiation protection. Due to the differences in the nature of the long- and short-term effects, the BFO doses and effective dose equivalents are not cross-comparable. However, the authors aim to determine a strategy for regolith utilisation in a habitat for long-duration missions, for instance explaining how a specific SPE shelter area is required in a habitat, where the rest of it would cover the protection from GCR.

Using the female phantom model contributes to filling gender gaps in radiation protection research. However, the utilisation of more recent phantoms as well as the male sex models would complete this work further. Gender differences can be discussed in terms of dose absorption per organ, for BFO in particular, as well as the effective dose equivalent. The effects of radiation, both long and short term, such as carcinogenesis and vision impairment could be paired with specific organ doses and sex-disaggregated data analysed on the matter of gender differences. Such work may contribute to the formulation of engineering specifications for habitat construction, if for example the female phantom is chosen as the standard model for radiation protection on exploration type missions.

The utilisation of spherical geometries for all scenarios is a simplistic approach. Geometry affects the imparted doses and thus such an approximation is limited compared to real-life scenarios. However, when simulating the same radiation environments, this method allows to cross-compare the effectiveness of the used materials in their configurations. For example, the choice of a single geometry allows cross-comparing the cases of an astronaut performing an EVA on the surface of the Moon and their crewmate staying inside the habitat. It demonstrates the relative difference in radiation protection resulting from the change of shielding materials without the effect of geometry. However, future work will define and use geometries that better approximate the different real-life scenarios of a long-term mission on the lunar surface.

\section{Conclusions}

An overarching conclusion of this work supports current state-of-the-art on regolith utilisation for radiation protection $[6,16,56]$. It consists of three parts:

1. Regolith has a real potential for radiation protection of a surface habitat on the Moon.

2. Minimisation of secondary emissions should be targeted by specific materials in the habitat walls.

3. More diversified in situ measurements are necessary for a definite design of any habitat and closing the gap between simulations and real doses. 
Within the context of given model limitations, more specific conclusions can be drawn about the radiation protection of a habitat on the surface of the Moon, using OLTARIS surface function:

- To maintain the effective dose equivalent under $150 \mathrm{mSv}$ for 180 days, the habitat needs at least $160 \mathrm{~g} / \mathrm{cm}^{2}$ of highlands regolith shielding. That corresponds to $100 \mathrm{~cm}$ at the nominal volumetric density of $1.6 \mathrm{~g} / \mathrm{cm}^{3}$, or $40 \mathrm{~cm}$ of regolith compressed to $4.0 \mathrm{~g} / \mathrm{cm}^{3}$.

- The habitat should rather have a multilayer shield with for instance $8.5 \mathrm{~cm}$ of highlands regolith compressed to $2.7 \mathrm{~g} / \mathrm{cm}^{3}$, followed by $3 \mathrm{~mm}$ of aluminium and $5 \mathrm{~cm}$ of polyethylene.

- For the shelter, the shield must comprise a multilayer structure with at least $405 \mathrm{~g} / \mathrm{cm}^{2}$ of regolith. That corresponds to $150 \mathrm{~cm}$ of $2.7 \mathrm{~g} / \mathrm{cm}^{3}$ regolith and $5 \mathrm{~cm}$ of polyethylene.

- Due to the long-term unpredictability of SPE occurrences in future solar cycles, the shelter area has to be designed with large margins. The option of adding more layers inside the habitat as materials become available during a mission should be considered. In particular, most of the tools, items, food portions are typically packed in plastic bags for the travel. Plastic compression techniques should be evaluated for production of supplementary shielding from used materials and plastic bags in particular.

Native highlands regolith has good thermal insulation properties which could save a lot of heating energy inside a habitat, whatever the extreme external temperatures are on the surface of the Moon during days or nights. A considerable part of the simulated habitat wall remains largely unaffected by the thermal cycling and temperature constraints. Compressed regolith provides an additional benefit of $\frac{1}{4}$ of the wall's thickness that remains in isothermal state. This concludes that both for radiation protection and thermal insulation of habitats, regolith compression is desirable.

Finally, having taken the CAF model as a reference in this study, the results show that female astronauts may not suffer excessively of the radiation exposure if the proposed solutions are followed. Mixed crews can stay safely on the surface of the Moon for extended periods of time, if appropriate protection guidelines are followed. Future work will use the newer Female Adult voXel 2005 (FAX) anatomical model, possibly cross-comparing results with CAF, as well as male phantoms. Further, we aim to compare the results to those from probabilistic models and experimental data with biological materials irradiated behind prototype walls.

Author Contributions: Conceptualization, Y.A. and Y.G.; methodology, Y.A.; simulations, Y.A.; validation, Y.A. and Y.G.; formal analysis, Y.A.; investigation, Y.A.; resources, Y.A.; writing-original draft preparation, Y.A.; writing-review and editing, Y.A.; visualization, Y.A.; supervision, Y.G.; project administration, Y.G.; funding acquisition, Y.G. All authors have read and agreed to the published version of the manuscript.

Funding: This study was supported by the Department of Mechanics, Structures and Materials of ISAE-SUPAERO, l'Institut Supérieur de l'Aéronautique et de l'Espace.

Conflicts of Interest: The authors declare no conflict of interest.

\section{References}

1. ICRP. ICRP Publication 123: Assessment of radiation exposure of astronauts in space. Ann. ICRP 2013, 42, 1-339. [CrossRef]

2. Huff, J.; Carnell, L.; Blattnig, S.; Chappell, L.; George, K.; Lumpkings, S.; Simonsen, L.; Slaba, T.; Werneth, C. Evidence Report: Risk of Radiation Carcinogenesis; NASA Lyndon B. Johnson Space Center: Houston, TX, USA, 2016.

3. Durante, M.; Cucinotta, F.A. Physical basis of radiation protection in space travel. Rev. Mod. Phys. 2011, 83, 1245-1281. [CrossRef]

4. Malla, R.B.; Brown, K.M. Determination of temperature variation on lunar surface and subsurface for habitat analysis and design. Acta Astronaut. 2015, 107, 196-207. [CrossRef]

5. Benaroya, H.; Bernold, L. Engineering of lunar bases. Acta Astronaut. 2008, 62, 277-299. [CrossRef]

6. Pham, T.T.; El-Genk, M.S. Dose estimates in a lunar shelter with regolith shielding. Acta Astronaut. 2009, 64, 697-713. [CrossRef]

7. Cesaretti, G.; Dini, E.; De Kestelier, X.; Colla, V.; Pambaguian, L. Building components for an outpost on the Lunar soil by means of a novel 3D printing technology. Acta Astronaut. 2014, 93, 430-450. [CrossRef] 
8. Moses, R.W.; Bushnell, D.; Komar, D.R.; Choi, S.; Litchford, R.; Chang-Diaz, F.; Carter, M. Maintaining Human Health for Humans-Mars. In AIAA Space and Astronautics Forum and Exposition; AIAA Aerospace Research Central: Orlando, FL, USA, 2018. [CrossRef]

9. Adams, J.; Hathaway, D.; Grugel, R.; Watts, J.; Parnell, T.; Gregory, J.; Winglee, R. Revolutionary Concepts of Radiation Shielding for Human Exploration of Space; NASA Marshall Space Flight Center: Huntsville, AL, USA, 2005.

10. Bond, D.; Goddard, B.; Singleterry, R.; León, S.B.Y.; Leóna, S.B.Y. Evaluating the effectiveness of common aerospace materials at lowering the whole body effective dose equivalent in deep space. Acta Astronaut. 2019, 165, 68-95. [CrossRef]

11. Yucker, W.R.; Huston, S.L. The Computerized Anatomical Female; McDonnell Douglas Company: St. Louis, MO, USA, 1990.

12. Yucker, W.R.; Reck, R.J. Computerized Anatomical Female Body Self-Shielding Distributions; McDonnell Douglas Company: St. Louis, MO, USA, 1992.

13. Smith, M.; Craig, D.; Herrmann, N.; Mahoney, E.; Krezel, J.; McIntyre, N.; Goodliff, K. The Artemis program: An overview of NASA's activities to return humans to the Moon. In Proceedings of the IEEE Aerospace Conference, Big Sky, MT, USA, 7-14 March 2020.

14. SSK: German Commission on Radiological Protection. Sex-specific differences in radiation sensitivity-Epidemiological, clinical and biological studies. In Proceedings of the 236th Meeting of the German Commission on Radiological Protection, Bonn, Germany, 17-18 September 2009.

15. Durante, M. Space radiation protection: Destination Mars. Life Sci. Space Res. 2014, 1, 2-9. [CrossRef] [PubMed]

16. Meurisse, A.; Cazzaniga, C.; Frost, C.; Barnes, A.; Makaya, A.; Sperl, M. Neutron radiation shielding with sintered lunar regolith Radiat. Meas. 2020, 132, 106247. [CrossRef]

17. Buchner, C.; Pawelke, R.H.; Schlauf, T.; Reissner, A.; Makaya, A. A new planetary structure fabrication process using phosphoric acid. Acta Astronaut. 2018, 143, 272-284. [CrossRef]

18. Jakus, A.E.; Koube, K.D.; Geisendorfer, N.R.; Shah, R.N. Robust and Elastic Lunar and Martian Structures from 3D-Printed Regolith Inks. Sci. Rep. 2017, 7, srep44931. [CrossRef] [PubMed]

19. Narici, L.; Casolino, M.; di Fino, L.; Larosa, M.; Picozza, P.; Rizzo, A.; Zaconte, V. Performances of Kevlar and Polyethylene as radiation shielding on-board the International Space Station in high latitude radiation environment. Sci. Rep. 2017, 7, 1-11. [CrossRef] [PubMed]

20. Walsh, L.; Schneider, U.; Fogtman, A.; Kausch, C.; McKenna-Lawlor, S.; Narici, L.; Ngo-Anh, J.; Reitz, G.; Sabatier, L.; Santin, G.; et al. Research plans in Europe for radiation health hazard assessment in exploratory space missions. Life Sci. Space Res. 2019, 21, 73-82. [CrossRef] [PubMed]

21. Williams, R. NASA Space Flight Human-System Standard Volume 1, Revision A: Crew Health; NASA: Washington, DC, USA, 2015.

22. $\mathrm{Hu}, \mathrm{S}$. Solar Particle Events and Radiation Exposure in Space. 2017. Available online: https://three.jsc.nasa.gov/articles/HuSPEs.pdf (accessed on 17 May 2019).

23. Reitz, G.; Berger, T.; Matthiae, D. Radiation exposure in the moon environment. Planet. Space Sci. 2012, 74, 78-83. [CrossRef]

24. McKenna-Lawlor, S.; Bhardwaj, A.; Ferrari, F.; Kuznetsov, N.; Lal, A.; Li, Y.; Nagamatsu, A.; Nymmik, R.; Panasyuk, M.; Petrov, V.; et al. Feasibility study of astronaut standardized career dose limits in LEO and the outlook for BLEO. Acta Astronaut. 2014, 104, 565-573. [CrossRef]

25. National Oceanic and Atmosphere Administration. Solar Cycle 25 Preliminary Forecast. 2019. Available online: https://www. swpc.noaa.gov/news/solar-cycle-25-preliminary-forecast (accessed on 17 May 2019).

26. Kim, M.-H.Y.; De Angelis, G.; Cucinotta, F.A. Probabilistic assessment of radiation risk for astronauts in space missions. Acta Astronaut. 2011, 68, 747-759. [CrossRef]

27. Marusek, J.A. Forecast for Solar Cycle 25. 2018. Available online: https:/ / wattsupwiththat.com/2018/02/09/forecast-for-solarcycle-25/ (accessed on 23 April 2021).

28. Pham, T.T.; El-Genk, M.S. Regolith Biological Shield for a Lunar Outpost from High Energy Solar Protons. In AIP Conference Proceedings 969; AIP Publishing: College Park, MD, USA, 2008; Volume 969, pp. 474-483.

29. Heilbronn, L. Neutron Properties and Definitions; NASA: Washington, DC, USA, 2015.

30. Haruyama, J.; Morota, T.; Kobayashi, S.; Sawai, S.; Lucey, P.G.; Shirao, M.; Nishino, M.N. Lunar Holes and Lava Tubes as Resources for Lunar Science and Exploration. In Moon; Springer: Berlin/Heidelberg, Germany, 2012; pp. $139-163$.

31. Coombs, C.R.; Hawke, B.R. A search for intact lava tubes on the Moon: Possible lunar base habitats. In Proceedings of the Second Conference on Lunar Bases and Space Activities of the 21st Century, Houston, TX, USA, 5-7 April 1988.

32. De Angelis, G.; Wilson, J.W.; Clowdsley, M.S.; Nealy, J.E.; Humes, D.H.; Clem, J.M. Lunar Lava Tube Radiation Safety Analysis. J. Radiat. Res. 2002, 43, S41-S45. [CrossRef]

33. Jaumann, R.; Hiesinger, H.; Anand, M.; Crawford, I.; Wagner, R.; Sohl, F.; Jolliff, B.; Scholten, F.; Knapmeyer, M.; Hoffmann, H.; et al. Geology, geochemistry, and geophysics of the Moon: Status of current understanding. Planet. Space Sci. 2012, 74, 15-41. [CrossRef]

34. McKay, D.S.; Heiken, G.; Basu, A.; Blanford, G.; Simon, S.; Reedy, R.; French, B.M.; Papike, J. The Lunar Regolith. In Lunar Sourcebook; Cambridge University Press: Cambridge, UK, 1991; pp. 285-356.

35. Singleterry, R.C.; Blattnig, S.R.; Clowdsley, M.S.; Qualls, G.D.; Sandridge, C.A.; Simonsen, L.C.; Slaba, T.C.; Walker, S.A.; Badavi, F.F.; Spangler, J.L.; et al. OLTARIS: On-line tool for the assessment of radiation in space. Acta Astronaut. 2011, 68, $1086-1097$. [CrossRef] 
36. Wilson, J.; Badavi, F.F.; Cucinotta, F.; Shinn, J.L.; Badhwar, G.D.; Silberberg, R.; Tsao, C.H.; Townsend, L.W.; Tripathi, R. Hzetrn: Description of a Free-Space Ion and Nucleon Transport and Shielding Computer Program; NASA: Hampton, VA, USA, 1995.

37. Wilson, J.W.; Tripathi, R.K.; Mertens, C.J.; Blattnig, S.R.; Clowdsley, M.S.; Cucinotta, F.A.; Tweed, J.; Heinbockel, J.H.; Walker, S.A.; Nealy, J.E. Verification and Validation: High Charge and Energy (HZE) Transport Codes and Future Development; NASA: Hampton, VA, USA, 2005.

38. O'Neill, P. Badhwar-O'Neill galactic cosmic ray model update based on advanced composition explorer (ACE) energy spectra from 1997 to present. Adv. Space Res. 2006, 37, 1727-1733. [CrossRef]

39. Usoskin, I.G.; Bazilevskaya, G.A.; Kovaltsov, G.A. Solar modulation parameter for cosmic rays since 1936 reconstructed from ground-based neutron monitors and ionization chambers. J. Geophys. Res. Space Phys. 2011, 116, 02104. [CrossRef]

40. NASA. OLTARIS User Guide; NASA: Washington, DC, USA.

41. King, J.H. Solar Proton Fluences for 1977-1983 Space Missions. J. Spacecr. Rocket. 1974, 11, 401-408. [CrossRef]

42. Wilson, J.W.; Townsend, L.W.; Schimmerling, W.; Khandelwal, G.S.; Khan, F.; Nealy, J.E.; Cucinotta, F.A.; Simonsen, L.C.; Shinn, J.L.; Norbury, J.W. Transport Methods and Interactions for Space Radiations. Biol. Eff. Phys. Sol. Galact. Cosm. Radiat. Part B 1993, 187-786. [CrossRef]

43. Sauer, H.H.; Zwickl, R.D.; Ness, M.J. Summary Data for the Solar Energetic Particle Events of August through December 1989; Space Environment Laboratory: Houston, TX, USA, 1990.

44. Jiggens, P.; Chavy-Macdonald, M.-A.; Santin, G.; Menicucci, A.; Evans, H.; Hilgers, A. The magnitude and effects of extreme solar particle events. J. Space Weather Space Clim. 2014, 4, 1-16. [CrossRef]

45. Xu, F.; Jia, X.; Lu, W.; Zhou, C.; Guo, Y.; Fei, J.; Yang, C. Utilization of trash for radiation protection during manned space missions. Acta Astronaut. 2018, 151, 585-594. [CrossRef]

46. Ewert, M.; Broyan, J.; Goodliff, K.; Clowdsley, M.; Singleterry, R. Comparing trash disposal and reuse options for Deep Space Gateway and Mars missions. In AIAA Space and Astronautics Forum and Exposition; AIAA Aerospace Research Central: Orlando, FL, USA, 2017.

47. Ewert, M.K.; Broyan, J.L.; Semones, E.J.; Goodliff, K.E.; Chai, P.R.; Singleterry, R.C.; Abston, L.; Clowdsley, M.S.; Witt-kopp, C.J.; Vitullo, N.A. Comparing trash disposal to use as radiation shielding for a Mars transit vehicle. In Proceedings of the 47th International Conference on Environmental Systems, Charleston, SC, USA, 16-20 July 2017.

48. ESA. SPENVIS-Prediciting Solar Proton Events. 2018. Available online: https://www.spenvis.oma.be/help/background/flare/ flare.html\#PRED (accessed on 2 September 2019).

49. Yu, S.; Fa, W. Thermal conductivity of surficial lunar regolith estimated from Lunar Reconnaissance Orbiter Diviner Radiometer data. Planet. Space Sci. 2016, 124, 48-61. [CrossRef]

50. Sakatani, N.; Ogawa, K.; Arakawa, M.; Tanaka, S. Thermal conductivity of lunar regolith simulant JSC-1A under vacuum. Icarus 2018, 309, 13-24. [CrossRef]

51. Balasubramaniam, R.; Wegeng, R.; Gokoglu, S.; Suzuki, N.; Sacksteder, K. Analysis of solar-heated thermal wadis to support extended-duration lunar exploration. In Proceedings of the 47th AIAA Aerospace Sciences Meeting Including the New Horizons Forum and Aerospace Exposition, Orlando, FL, USA, 5-8 January 2009.

52. Hayne, P.O.; Bandfield, J.L.; Siegler, M.A.; Vasavada, A.R.; Ghent, R.R.; Williams, J.-P.; Greenhagen, B.T.; Aharonson, O.; Elder, C.M.; Lucey, P.G.; et al. Global regolith thermophysical properties of the Moon from the Diviner Lunar Radiometer Experiment. J. Geophys. Res. Planets 2017, 122, 2371-2400. [CrossRef]

53. Whipple, F.L. A comet model. I. The acceleration of Comet Encke. Astrophys. J. 1950, 111, 375-394. [CrossRef]

54. Fateri, M.; Sottong, R.; Kolbe, M.; Gamer, J.; Sperl, M.; Cowley, A. Thermal properties of processed lunar regolith simulant. Int. J. Appl. Ceram. Technol. 2019, 16, 2419-2428. [CrossRef]

55. Lagrée, P.-Y. Le coefficient d'échange h, applications en 1D et aux Ailettes. 2010. Available online: http://www.lmm.jussieu.fr/ $\sim\{\}$ lagree/COURS/MECAVENIR (accessed on 29 July 2020).

56. Miller, J.; Taylor, L.; Zeitlin, C.; Heilbronn, L.; Guetersloh, S.; DiGiuseppe, M.; Iwata, Y.; Murakami, T. Lunar soil as shielding against space radiation. Radiat. Meas. 2009, 44, 163-167. [CrossRef] 